\title{
Modelling shoreface profile evolution
}

\author{
Marcel J.F. Stive ${ }^{\mathrm{a}, \mathrm{b}}$, Huib J. de Vriend ${ }^{\mathrm{c}}$ \\ ${ }^{a}$ Netherlands Centre for Coastal Research, Delft University of Technology, Faculty of Civil Engineering, P.O. Box 5048, \\ 2600 GA Delft, The Netherlands \\ ${ }^{b}$ Delft Hydraulics, P.O. Box 152, 8300 AD Emmeloord, The Netherlands \\ ${ }^{c}$ University of Twente, Section Civil Engineering and Management, P.O. Box 217, 7500 AE Enschede, The Netherlands
}

Received 15 February 1994; revision accepted 11 October 1994

\begin{abstract}
Current knowledge of hydro-, sediment and morpho-dynamics in the shoreface environment is insufficient to undertake shoreface-profile evolution modelling on the basis of first physical principles. We propose a simple, paneltype model to map observed behaviour. The internal dynamics are determined by slope-dependent, wave-induced cross-shoreface transports, while the external driving factors are lateral sediment supply and sea-level rise. This model concept is tested with reasonable success against the obscrved bchaviour of the Central Holland Coast, considcring two hindcast periods, one covering the evolution over the last century, the other the Subboreal/Subatlantic evolution.

A limitation of this model is that the cross-shoreface dynamics are solely steered by the variations of shoaling, short waves. Since a variety of other wave and current dynamics may be expected to be present in the coastal boundary layer, it may well be that the effects of the mechanisms and conditions which are not represented are hidden in the coefficients of the sediment-transport formula. This limits the accuracy of the coefficients as used, and our findings should be considered as an-order-of-magnitude estimate only. Indeed, behaviour-oriented modelling implies that generalization of results to arbitrary situations and conditions is not straightforward. Yet, we expect that some of the conclusions are more generally applicable.

This concerns the substantiation of the assumption that the upper shoreface responds on a much smaller time scale than the lower shoreface, and the idea that the shoreface profile is not always and everywhere in equilibrium with its forcing. A worthwhile observation from the Holland Coast application is, that the bottom slope effect on the transport is only important at geological time scales. The profile evolution at the engineering time scales (say 10 to 100 years) is effectively quasi-static, in that there is no feedback between the long-term averaged transport and the state of the profile. This implies that at these smaller scales the profile changes can be predicted on the basis of a static sediment balance. This does not mean that the gravitational downslope transport is unimportant as a physical phenomenon in coastal profile evolution: It is only unimportant if a highly aggregated model like this is applied at relatively short time scales.
\end{abstract}

\section{Introduction}

It can be rightfully argued (cf. Pilkey et al., 1993 ) that there exists an unsatisfactory discrepancy between the concepts of the shoreface evolution models in use among geologists and those utilized by coastal engineers. The former are generally based on geometric laws, obeying the conser- vation of mass while taking account of important geologic observations (Cowell et al., 1992, 1994). In addition to the use of conservation of mass, coastal engineering shoreface-protile models (e.g. Dean, 1991) introduce semi-empirical laws regarding the dynamic response of the profile to wave action. The majority of the discrepancies between these approaches is connected with either the time 
scale of the evolutions considered (cf. Inman et al., 1993), or with the somehow related question of the range of water depths to which the concept is to be applied. Therefore, we will attempt to unify some of these concepts into a shoreface-evolution modelling approach, which reveals that the relevancy of certain physical processes depends on the time scale at which the profile evolution actually takes place.

We limit ourselves to coastal stretches which have some form of superstructure like a dune preventing overwash, and which are not interrupted by inlet systems nor constrained by underlying or nearby geology. Furthermore, it is implicit that this coastal stretch is approximately uniform in the longshore direction both as far as it concerns the profile form, loose-sediment substrate characteristics and extrinsic hydrodynamic conditions. Effectively, this implies that we consider the average shoreface profile evolution of coastal stretches or cells of several kilometres in length, which are part of an uninterrupted coastline with small curvature.

On the shoreface of such a coastal cell a variety of hydrodynamic and sediment-transport processes are interacting with the bed, as indicated in Fig. 1. In contrast with some of the literature (e.g. Niedoroda and Swift, 1991) we include the surfzone, beach and dune face in the shoreface definition, and it is thus the zone between the top of the dune face and the inner continental shelf which is morphologically active at large time scales. The nature of the hydrodynamics (waves, currents and circulation) in the surf zone is different from that on the remainder of the shoreface. In the surf zone the processes are strongly depth controlled and largcly driven by the associated loss of momentum and the dissipation of wave energy (cf. Battjes et al., 1991). Wave propagation, circulation and currents on the remainder of the shoreface are influenced by the shoaling water depths and shoreline position, but in this coastal bcundary layer many external forces, such as friction, pressure gradients and geostrophic effects and baroclinic forces, are driving circulation and currents, while density differences may also play an important role. Physical aspects and relevant field observations of these coastal boundary layer circulations on a variety of event scales are discussed by Niedoroda and Swift (1991).

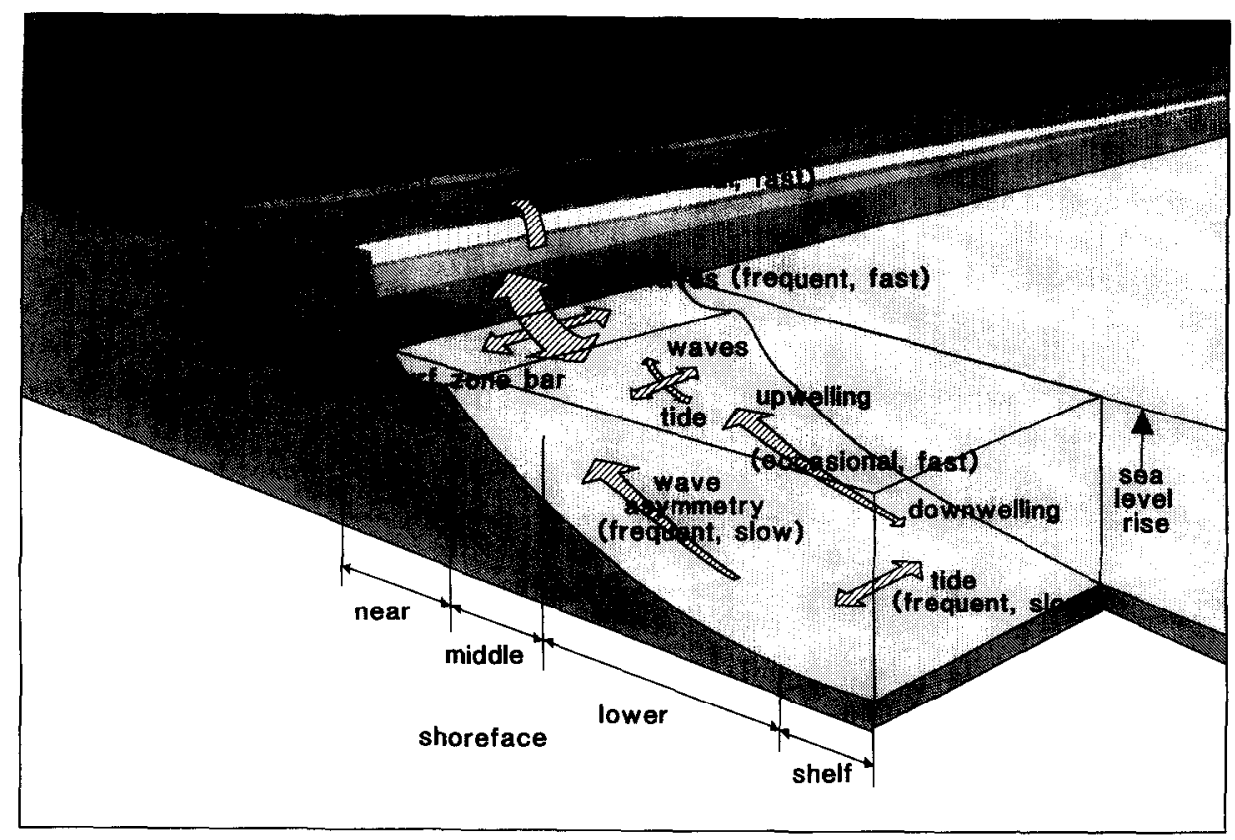

Fig. 1. Overview of hydrodynamic processes on the shoreface (modified after Stive et al., 1990). 
Our starting hypothesis is that, in line with the above hydrodynamic differentiation, we may distinguish two distinct morphodynamic regimes in the long-term morphological evolution of the shoreface profile, viz. (1) the upper shoreface which includes the dune face, beach, inner and outer surfzone, and where the effects due to wave energy dissipation are predominant, and (2) the lower shoreface through to its inner-shelf foot where the mixed action of shoreface currents and shoaling and refracting waves is predominant. The upper shoreface, often called the 'active zone' in the literature on short-term profile evolution, is assumed to obey more or less the assumption of invariance of the profile relative to the mean sea level (cf. Bruun, 1962). This implies that the morphodynamic adaptation of the profile is assumed to be relatively fast. The lower shoreface in contrast undergoes relatively slow adaptations to the changes of the currents and waves caused by such things as changes of the mean sea level. The transition zone between these regimes, the middle shoreface, is assumed to adapt itself to the changes imposed by the upper and lower shoreface behaviour.

An overview of the general behaviour and possible displacements of the several cross-shore profile zones and of the steering processes is as summarized in Table 1.

Based on the above analysis we conclude that on a large time scale the whole shoreface profile is "active", but that the dynamic profile response takes place at different time scales. Observations suggest time scales of hours around the waterline (e.g. Lippmann and Holman, 1989) to millennia near the inner shelf (e.g. Niedoroda and Swift, 1991). This has an important consequence for the intrinsic shoreface behaviour: since nearequilibrium behaviour only applies where the dynamic response scale is fast relative to the time scale of changes in the extrinsic (driving) conditions (such as mean sea level, wave and current climate, sediment supplies), shoreface evolution is transient by definition. This implies that we reject the idea that shoreface profiles may be assumed to have a fixed shape which only depends on mean sediment and wave climate characteristics. This shape invariance may hold well for the upper
Table 1

Large-scale evolution of a coastal stretch

\begin{tabular}{ll}
\hline Profile zone & Behaviour and displacement \\
\hline Upper shoreface & Steady profile form (yearly averaged) \\
& Upward profile displacement with \\
& sea-level rise \\
& Shorcward horizontal profile \\
& displacement due to: \\
& - upward profile displacement with \\
& sea-level rise \\
& - aeolian transport over first dune \\
& row \\
& - positive alongshore transport \\
& gradient (alongshore loss) \\
& - downwelling transport on shoreface \\
& Seaward horizontal profile \\
& displacement due to: \\
& - wave asymmetry and upwelling \\
& transport on shoreface \\
& - negative alongshore transport \\
& gradient (alongshore gain) \\
Inner shelf & Inclining or declining depending on: \\
Lower shoreface & - horizontal upper shoreface \\
& displacement \\
& - declining or inclining lower \\
& shoreface \\
& Declining (and eroding) in case of: \\
& - dominance of wave asymmetry and \\
& upwelling transport \\
& - negative alongshore transport \\
& gradient \\
& Inclining (and accreting) in case of: \\
& - dominance of downwelling \\
& - positive alongshore transport \\
Middle shoreface & \\
& \\
& \\
& \\
& \\
&
\end{tabular}

region of the shoreface where the dynamic adaptation is fast relative to the driving conditions, possibly even at the seasonal scale (Inman et al., 1993).

Taking this into account we apply geometric rules to the above profile zones based upon mass conservation between these zones, including sources and sinks due to such effects as gradients in the alongshore transport. Additionally, we introduce the cross-profile sediment transport, which is related to wave action, water depth and mean bottom slope in each zone. As a consequence, the 
sediment balance is no longer purely geometric: it takes time for the sediment to be transported to where it is needed according to the geometric "demand". Thus we have made the model transient, instead of quasi-static.

With this modelling concept we investigate two different evolution stages of the shoreface profile of the Holland coast, viz. (1) the Subboreal/ Subatlantic evolution from approximately 5000 to 2200 yrs B.P. and (2) the recent behaviour over approximately the last century.

\section{Profile schematization and geometric rules}

The most simple schematization of the profile shape which we may apply to follow our approach distinguishes between the dune face, the upper shoreface, the middle or transitional shoreface and the lower shoreface (see Fig. 2). The lower shoreface is assumed to reach a region, say the inner shelf, where the morphodynamic changes are so slow that on the timescales considered there exist no significant changes. In line with our approach, the dune face and the upper shoreface maintain their shape relative to mean sea level, while obeying the law of mass conservation. The lower shoreface is assumed to be subject to changes induced solely by the cross-shoreface transport at the transition to the middle shoreface and thus rotates only around the inner shelf base. The middle shoreface covers that region of the shoreface profile, where

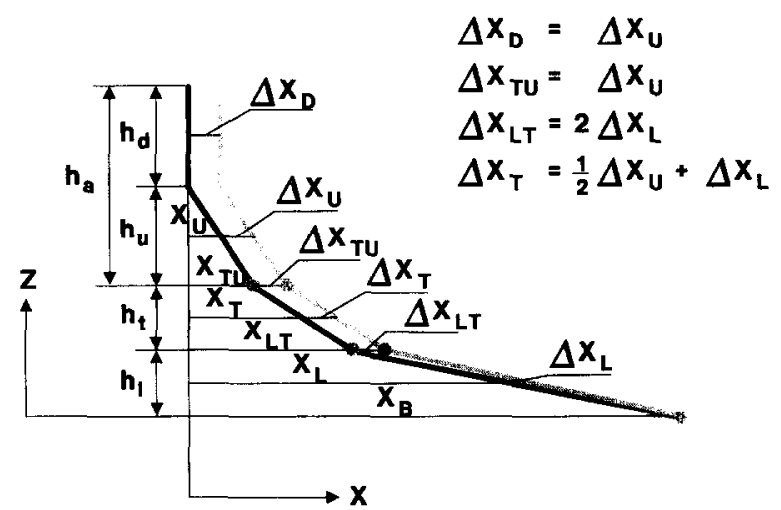

Fig. 2. Model schematization of the shoreface profile into three hinged, rigid panels. the depth-of-closure (Hallermeier, 1981) is approximately located, i.e. the depth beyond which we may not observe measurable changes of the profile from yearly profile measurements. In addition to the cross-shoreface transport gradients, which are dependent on the profile state, we allow for sources and sinks due to longshore-induced effects or human interventions like sediment extraction, which are independent of the profile dynamics.

The profile geometry is thus given by the vertical extent of the different zones and their mean distances to an arbitrary vertical reference line (also see Fig. 2):

- the height and mean offshore position of the upper shoreface, including the dune: $h_{\mathrm{A}}=h_{\mathrm{D}}+h_{\mathrm{U}}$ and $x_{\mathrm{U}}$;

- the height and mean extent of the transition zone: $h_{\mathrm{T}}$ and $x_{\mathrm{T}}$; and

the height and mean extent of the lower shoreface: $h_{\mathrm{L}}$ and $x_{\mathrm{L}}$.

The geometric relations between changes in the profile sections according to the above approach, in terms of deviations from the initial profile, are therefore:

$$
\begin{aligned}
& \Delta x_{\mathrm{D}}=\Delta x_{\mathrm{U}}, \\
& \Delta x_{\mathrm{TU}}=\Delta x_{\mathrm{U}}, \\
& \Delta x_{\mathrm{LT}}=2 \Delta x_{\mathrm{L}}, \\
& \Delta x_{\mathrm{T}}=1 / 2 \Delta x_{\mathrm{U}}+\Delta x_{\mathrm{L}},
\end{aligned}
$$

with the related volume changes per unit width:

$$
\begin{aligned}
& \Delta A_{\mathrm{A}}=h_{\mathrm{A}} \Delta x_{\mathrm{U}}, \\
& \Delta A_{\mathrm{T}}=h_{\mathrm{T}}\left(1 / 2 \Delta x_{\mathrm{U}}+\Delta x_{\mathrm{L}}\right), \\
& \Delta A_{\mathrm{L}}=h_{\mathrm{L}} \Delta x_{\mathrm{L}} .
\end{aligned}
$$

The time variation of the unit-width profile volume per section follows from mass conservation and leads to the state descriptions:

$$
\begin{aligned}
& \mathrm{d}\left(\Delta A_{\mathrm{A}}\right) / \mathrm{d} t=C_{\mathrm{AEOL}}-C_{\mathrm{TU}}+\Delta L_{\mathrm{U}}+Q_{\mathrm{U}} \\
& \mathrm{d}\left(\Delta A_{\mathrm{T}}\right) / \mathrm{d} t=C_{\mathrm{TU}}-\mathrm{C}_{\mathrm{LT}}+\Delta L_{\mathrm{T}} \\
& \mathrm{d}\left(\Delta A_{\mathrm{L}}\right) / \mathrm{d} t=C_{\mathrm{LT}}-C_{\mathrm{B}}+\Delta L_{\mathrm{L}}+Q_{\mathrm{L}}
\end{aligned}
$$

in which

$t$ is time,

$C_{\mathrm{AEOL}}$ the aeolian transport over the first dunerow,

$C_{\mathrm{TU}}$ the cross-shoreface transport at the transition between upper and middle shoreface,

$C_{\mathrm{LT}}$ the cross-shoreface transport at the transition between middle and lower shoreface, 
$C_{\mathrm{B}}$ the "autonomous" cross-shoreface transport at the transition between lower shoreface and inner shelf,

$\Delta L_{\mathrm{U}, \mathrm{T}, \mathrm{L}}$ the longshore transport gradients over the profile section, and

$Q_{\text {U.L }}$ source terms to simulate continuous sources or sinks.

Alongshore transport gradients are taken into account via the source terms $\Delta L_{\mathrm{U}, \mathrm{T}, \mathrm{L}}$, which at this stage are assumed to be known input functions of time. A possible extension of the model can be to consider a dependence of the longshore transport gradients as a function of coastline orientation relative to the incident wave driving directions. We refrain from this extension, since it is not essential for our present objectives, which centre around the role of cross-shoreface dynamics. As we also assume the other (anthropogenic) source and sink functions to be known functions of time, we now have to model the cross-shoreface transports at the transitions between upper, middle and lower shoreface as a function of wave conditions, water depth and bottom slope. This is addressed in the following section.

\section{Cross-shoreface transport formulation}

It could be argued that long-term mean sediment transport due to the combined action of currents of different origin (wind driven, density driven, tide driven, wave driven and all of these Coriolisinfluenced) and shoaling waves on the shoreface, including the effects of bottom slope, is insufficiently known to be incorporated in a long-term model. In principle, this may be true, but a simple modelling approach, based on current insights, would at least allow us to derive the relative variation with depth and wave action over the cross-shoreface profile, given the net crossshoreface transport at an arbitrary depth. The least we can gain from this is a test of existing models in their capability to simulate the transport distribution on the shoreface.

In pursuit of this approach we adopt the transport formulation of Bagnold (1963) as adapted by Bowen (1981), which gives the cross-shoreface bedload and suspended load transport as a func- tion of depth, wave action, current velocity and bottom slope. In adopting this we assume that the cross-shoreface variations are primarily induced by changes in net currents and waves due to depth variations. This is of course a simplification, but let us assume that this is allowed for a first order approximation. We thus introduce the following cross-shoreface transport formula:

$$
\begin{aligned}
& \frac{i}{C_{\mathrm{f}} \rho}=u_{0}^{2}\left[\frac{3 \varepsilon_{\mathrm{b}}}{4 \tan \phi}\left(2 u_{1}+u_{2}+\frac{16}{9 \pi} \frac{\tan \beta}{\tan \phi} u_{0}\right)+\right. \\
& \left.\frac{16}{15 \pi} \frac{\varepsilon_{\mathrm{s}} u_{0}}{w}\left(5 u_{1}+3 u_{2}+\frac{\tan \beta}{w} u_{0}^{2}\right)\right]
\end{aligned}
$$

where $i$ is the submerged total time-averaged sediment transport, bedload and suspended load combined,

$C_{\mathrm{f}}$ is a friction factor,

$\rho$ a relative density,

$\varepsilon_{\mathrm{b}}$ and $\varepsilon_{\mathrm{s}}$ efficiency factors for bedload and suspended load respectively,

$\tan \beta$ the local profile slope,

$\tan \phi$ the internal friction angle, and

$w$ the sediment's fall velocity.

The wave contributions are contained in $u_{0}$ and $u_{2}$, and according to the second-order Stokes' approximation read:

$u_{0}=\frac{a \sigma}{\sinh k h}, \quad u_{2}=\frac{3}{4} \frac{a^{2} \sigma \mathrm{k}}{\sinh ^{4} k h}$

where $a$ is the wave amplitude,

$\sigma$ the wave frequency,

$k$ the wave number, and

$h$ the mean water depth.

The flow contribution due to the mean bottom drift induced by the wave boundary layer is contained in $u_{1}$, and according to LonguetHiggins' (1953) conduction solution reads:

$u_{1}=\frac{3}{4} \frac{a^{2} \sigma \mathrm{k}}{\sinh ^{2} k h}$

Both the second-order Stokes' asymmetry and the Longuet-Higgins' mean drift approximations are defendable assumptions, since their application is limited to the middle shoreface region.

The relative importance of the wave asymmetry 
and drift terms depends on ratios involving $\varepsilon_{\mathrm{b}}$ and $\varepsilon_{\mathrm{s}}, \tan \phi$ and $w$. Taking Bagnold's suggestions that $\varepsilon_{\mathrm{s}} \approx 0.01, \varepsilon_{\mathrm{b}} / \tan \phi \approx 0.15$, Bowen shows that both the ratio between the drift terms and the asymmetry terms, as well as the ratios between suspended-load and bed-load transport can be approximated by:

$\frac{\text { drift terms }}{\text { asymmetry terms }} \approx \frac{\text { suspended load }}{\text { bedload }} \approx \frac{1}{15} \frac{u_{0}}{w}$

As we show in the Appendix it follows that in the particular case of our interest, i.e. in the shoreface transition region of the Central Holland coast, typical ratios are five to ten, which implies that suspended load contributions are dominant. We therefore disregard bedload in the following. Furthermore, as we wish to describe the evolution of the shape of the shoreface profile, it is sufficient to model the space- and time-variation of the transport with respect to a constant reference transport. The latter can be treated as a calibration constant, which can be determined from the overall sediment balance for a measured profile evolution. This implics that we use Bowen's suspended-load formulation solely to derive the variation with depth, wave conditions and bottom slope relative to a reference cross-shoreface transport and to derive the relative magnitude of the wave asymmetry, the wave drift and the slope-induced terms. Thus the cross-shoreface transport, $C$, is related to the reference transport by:

$\frac{C(x)}{C_{\mathrm{ref}}}=\frac{\left[u_{0}^{3}\left(5 u_{1}+3 u_{2}+\frac{\tan \beta}{w} u_{0}^{2}\right)\right]_{x}}{\left[u_{0}^{3}\left(5 u_{1}+3 u_{2}+\frac{\tan \beta}{w} u_{0}^{2}\right)\right]_{\mathrm{ref}}}$

The relative magnitude of the various terms at a particular depth may be found from the ratios:

$C_{\text {drift }}: C_{\text {asymmetry }}: C_{\text {slope }}=1: \frac{3}{5} \frac{1}{\sinh ^{2} k h}: \frac{4}{15} \frac{\tan \beta}{w} \frac{\sigma}{k}$

This result will be used to estimate the effect of the bottom slope on the cross-shoreface transport.

At this point it should be mentioned that in a later version of the Bowen model Bailard (1981) suggested the inclusion of $\varepsilon_{\mathrm{s}}$ in the last term of the above equation. This means effectively that autosuspension will not occur for $\tan \beta \rightarrow w / u_{0}$ but rather only for $\tan \beta \rightarrow w /\left(u_{0} \varepsilon_{\mathrm{s}}\right)$, an assumption which seems difficult to defend. Anyhow, the verification of this debate is one of the objectives of the present work, and will be discussed later.

In the following applications for the evolution of the Central Holland coastal system we use another result from the Appendix, i.e. that the dominating contributions by the wave conditions are centred around $H_{\mathrm{s}}=4 \mathrm{~m}$. In fact, we have selected only one representative condition of $H_{\mathrm{s}}=4.0 \mathrm{~m}$. and $T_{\mathrm{p}}=$ $7.25 \mathrm{~s}$. A further aspect which we have taken into account concerns the inclusion of cross-shoreface storm-surge level set-up, including a tidal excursion. In line with the cross-shoreface approach we adopt a tidal plus storm-surge level at an arbitrary reference position. The tidal level varies negligibly with depth, whereas we let the storm-surge level gradient vary inversely with depth.

\section{The effect of relative sea-level rise}

The inclusion of the effect of sea-level rise variations in our model is based upon the earlier assumptions about the respective response of the profile sections to sea-level rise. Since the upper shoreface zone is assumed to move vertically with the mean sea-level position, the height of the transition zone increases with the mean sea level.

The invariance of the upper shoreface and its constant vertical position relative to the mean sea level require that the state equations of our system are extended as follows:

$$
\begin{aligned}
\mathrm{d}\left(\Delta A_{\mathrm{A}}\right) / \mathrm{d} t= & C_{\mathrm{AEOL}}-C_{\mathrm{TU}}+\Delta L_{\mathrm{U}}+Q_{\mathrm{U}}+h_{\mathrm{U}} c_{\mathrm{p}} \\
\mathrm{d}\left(\Delta A_{\mathrm{T}}\right) / \mathrm{d} t= & C_{\mathrm{TU}}-C_{\mathrm{LT}}+\Delta L_{\mathrm{T}}+1 / 2 h_{\mathrm{T}} c_{\mathrm{p}} \\
& +x_{\mathrm{T}} \mathrm{d} M S L / \mathrm{d} t \\
\mathrm{~d}\left(\Delta A_{\mathrm{L}}\right) / \mathrm{d} t= & C_{\mathrm{LT}}-C_{\mathrm{B}}+\Delta L_{\mathrm{L}}+Q_{\mathrm{L}}
\end{aligned}
$$

in which $c_{\mathrm{p}}$ is the horizontal displacement speed of the upper shoreface.

If we assume an equilibrium situation with sealevel rise as the only source of excitation, we may derive:

$c_{\mathrm{p}}\left(h_{\mathrm{U}}+1 / 2 h_{\mathrm{T}}\right)+x_{\mathrm{T}} \mathrm{d} M S L / \mathrm{d} t=0$ 
from which we arrive at a slightly modified version of the Bruun-rule:

$c_{\mathrm{p}}=\left[x_{\mathrm{T}} /\left(h_{\mathrm{U}}+1 / 2 h_{\mathrm{T}}\right)\right] \mathrm{d} M S L / \mathrm{d} t$

The response of our system to excitations due to sea-level rise changes may be investigated analytically by introducing a linearization of the cross-shoreface transport changes at the transition between upper and transitional shoreface. Let us assume that-closely in line with Bowen's formulation-we may express $C_{\mathrm{TU}}$ as:

$C_{\mathrm{TU}}=C_{\mathrm{TU}}^{\mathrm{A}}+C_{\mathrm{TU}}^{\mathrm{M}}=C_{\mathrm{TU}}^{\mathrm{A}}+G_{\mathrm{TU}} \tan \beta$

in which $C$ is the total cross-shoreface transport, $C^{\mathrm{A}}$ is the autonomous component,

$C^{\mathrm{M}}$ is the morphologically determined component,

$G_{\mathrm{TU}}$ is a proportionality constant,

$\tan \beta$ is the bottomslope.

We now take a reference situation as our linearization point, and assume that the autonomous component undergoes no changes, so that we may express $C_{\mathrm{TU}}$ due to the excitation as:

$C_{\mathrm{TU}}=C_{\mathrm{TU}, \mathrm{ref}}+G_{\mathrm{TU}}\left(\tan \beta-\tan \beta_{\mathrm{ref}}\right)$

The mean bottom slope at the transition between the upper and lower shoreface can be expressed as a function of the excitation $\Delta A_{\mathrm{A}}$. In linear approximation this yields:

$$
\tan \beta=\tan \beta_{\text {ref }}+\alpha_{\mathrm{TU}} \Delta A_{\mathrm{A}}
$$

where $\alpha_{\mathrm{TU}}$ is a coefficient which can be derived from the reference profile, yielding:

$$
\begin{aligned}
\alpha_{\mathrm{TU}}= & \frac{1}{h_{\mathrm{U}}} \frac{1}{\left(x_{\mathrm{T}}-x_{\mathrm{TU}}\right)\left(x_{\mathrm{T}}-x_{\mathrm{U}}\right)} \\
& {\left[\left(2 x_{\mathrm{T}}-x_{\mathrm{U}}-x_{\mathrm{TU}}\right) \tan \beta_{\text {middle shoreface }}\right.} \\
& \left.-\left(x_{\mathrm{TU}}-x_{\mathrm{U}}\right) \tan \beta_{\text {upper shoreface }}\right]
\end{aligned}
$$

It is now interesting to note that if we assume a reference state which is in equilibrium, $C_{\mathrm{TU}, \mathrm{ref}}=0$ and

$$
\frac{\mathrm{d} \Delta A_{\mathrm{A}}}{\mathrm{d} t}=-G_{\mathrm{TU}} \alpha_{\mathrm{TU}} \Delta A_{\mathrm{A}}-\frac{h_{\mathrm{U}} x_{\mathrm{T}, \text { ref }}}{h_{\mathrm{U}}+\frac{1}{2} h_{\mathrm{T}, \text { ref }}} \frac{\mathrm{d} M S L}{\mathrm{~d} t}
$$

in which $\Delta A_{\mathrm{A}}$ stands for the deviation from the reference state.

This equation describes a relaxation process with inherent time scale $1 /\left(G_{\mathrm{TU}} \alpha_{\mathrm{TU}}\right)$ and the $M S L$-term as external forcing. This implies that the upper shoreface does not unconditionally follow the mean sea level as in the Bruun-rule, but that its vertical rise is dampened by the morphologically determined sediment transport from the transition zone. This seems to confirm the idea that application of the Bruun rule to the upper shoreface would lead to an overestimation of this zone's response to sea-level rise.

The degree to which this is indeed true may be found by evaluating the parameter values which steer the relaxation process. A non-instantaneous response will occur only if $1 /\left(G_{\mathrm{TU}}{ }^{\alpha} \mathrm{TU}\right)$ is of the same order as the time scale. If we introduce representative values for the autonomous transports, and for the wave conditions, bottom slopes and sediment fall velocities we may derive the order of magnitude of $G_{\mathrm{TU}}$ to be $10^{3} \mathrm{~m}^{3} / \mathrm{m} / \mathrm{yr}$ (using the earlier equation which expresses the ratios between the three contributions to the crossshoreface transport). A typical order of magnitude for $\alpha_{\mathrm{TU}}$ is $10^{-7} \mathrm{~m} / \mathrm{m}^{3}$. This implies that on time scales of 10 to 100 years $\Delta A_{\mathrm{A}}$ is proportional to the change in sea level, whence:

$$
\Delta A_{\mathrm{A}}=-\frac{h_{\mathrm{U}} x_{\mathrm{t}, \text { ref }}}{h_{\mathrm{U}}+\frac{1}{2} h_{\mathrm{T}, \text { ref }}} \Delta M S L
$$

At time scalcs of 1000 to 10,000 years, $\Delta A_{\mathrm{A}}$ exhibits an increasingly retarded response to the actual sea level, due to an increasing supply of sediment from the middle and lower shoreface. At even longer time scales, the model predicts an equilibrium state, in which $\Delta A_{\mathrm{A}}$ is no longer related to the actual sea level, but only to the rate of sealevel rise.

These conclusions will be verified in the discussions on the results obtained for the hindcast of the evolution of the Central Holland coast.

\section{Recent (1896-1975) evolution of the Central Holland Coast}

A rudimentary version of the present model, i.e. with the linearized version of the cross-shoreface 
transports and with their reference magnitudes on the panel transition levels as input variables, was applied successfully to the evolution of the Central Holland Coast over the last century (De Vriend et al., 1993). Here this application is repeated with the dynamic version of the cross-shoreface transport formulation.

A summary of long term observations (1896-1975) of the Holland Coast is presented in Fig. 3, after Knoester (1990). Our model is applied to a typical section ( $\mathrm{km} 70-90$, see Fig. 3 for location), which is characterized by small alongshore gradients, due to the nearly straight coast and the absence of adjacent inlets and structures (Table 2). The main driving process is that due to cross-shoreface transports induced primarily by wave asymmetry and nearbed wave driven flow, which latter is enhanced by density and wind driven upwelling (Stive and Eysink, 1989).

The profile schematization for the initial profile (1896) is given in Fig. 4, which is based on the historical positions of the waterline, the $7 \mathrm{~m}$ and the $10 \mathrm{~m}$ depth contours, and the present position of the shoreface to inner-shelf transition and present dune heights. The model basically requires three input parameters, which are kept constant over time, i.e.

(1) the rate of relative sea-level rise, which is taken as $\mathrm{d} M S L / \mathrm{d} t=0.0015 \mathrm{~m} / \mathrm{yr}$ (Stive and Eysink, 1989);

(2) the reference cross-shoreface transport rate $C_{\text {ref }}$, which is taken as $-3.0 \mathrm{~m}^{3} / \mathrm{m} / \mathrm{yr}$ at a reference

Table 2

Computed and observed profile displacements 1896-1975 section $\mathrm{km} 70-90$ Central Holland Coast

\begin{tabular}{lll}
\hline & Computed (m) & Observed (m) \\
\hline$\Delta x_{\mathrm{U}}$ & +24 & $+30 \pm 10$ \\
$\Delta x_{7 \mathrm{~m}}$ & -14 & $-25 \pm 15$ \\
$\Delta x_{10 \mathrm{~m}}$ & -70 & $-100 \pm 30$ \\
\hline
\end{tabular}

depth of $10 \mathrm{~m}$, with a characteristic wave height of $4.0 \mathrm{~m}$, a period of $7.25 \mathrm{~s}$ and a surge level of $2.0 \mathrm{~m}$;

(3) the net loss or gain of the upper shoreface due to aeolian transport over the dune face $\left(C_{\text {AEOL }}\right)$ and due to longshore transport gradients $\left(\Delta L_{\mathrm{U}}\right)$, which are estimated at -3.0 (loss) and +3.0 $\mathrm{m}^{3} / \mathrm{m} / \mathrm{yr}$ (gain), respectively (Stive and Eysink, 1989).

Based on the above initial geometry and input parameters the shoreface profile evolutions were computed. The comparison between observations and computations is made in the table below. It is concluded that the principal evolutions are reasonably well hindcasted. It appears that because of the absence of alongshore net losses in the upper shoreface the net feeding of this zone (primarily due to wave asymmetry and wave drift) can more than compensate for the losses due to the vertical profile movement with sea-level rise and windinduced transport. This causes the upper shoreface to prograde and the lower shoreface to flatten. As a result, the transition zone (or middle shoreface) between the upper shoreface and the lower shoreface steepens. It is noted that on the northern part of the Holland Coast alongshore losses in the upper shoreface are so large (Stive et al., 1990) that despite compensation due to wave asymmetry and wave drift feeding appreciable recession occurs. The recession is so strong that the middle shoreface flattens, even though the lower shoreface flattens as well.

A fundamental difference between the earlier application of the model and the present one lies in the formulation of the cross-shoreface transport. Here, we have used the method to derive the crossshoreface transport from the reference value as a function of depth, wave conditions and bottom slope, whereas in the earlier application the reference cross-shoreface transports at each panel transition level were input parameters. This means that we

Fig. 3. Long term observations (1896-1975) of the Holland Coast (after Knoester, 1990). Depth observations are given relative to the RSP baseline (full thin line with crosses every kilometer and the origin in the North at Den Helder), which was established in 1850 between the dunefoot and the high waterline. The hatchings around the $+3 \mathrm{~m}, 0 \mathrm{~m}$ and $-5 \mathrm{~m}$ contours are their yearly positions from the JARKUS profile database (1964-1986), the contours their average position. The $-7 \mathrm{~m}$ and $-10 \mathrm{~m}$ contours represent their average measured positions relative to the RSP baseline as taken from a campaign conducted over $1895-1898$ and from the 1965/1970/1975/1980 profile measurements (DOORLODINGEN database). 


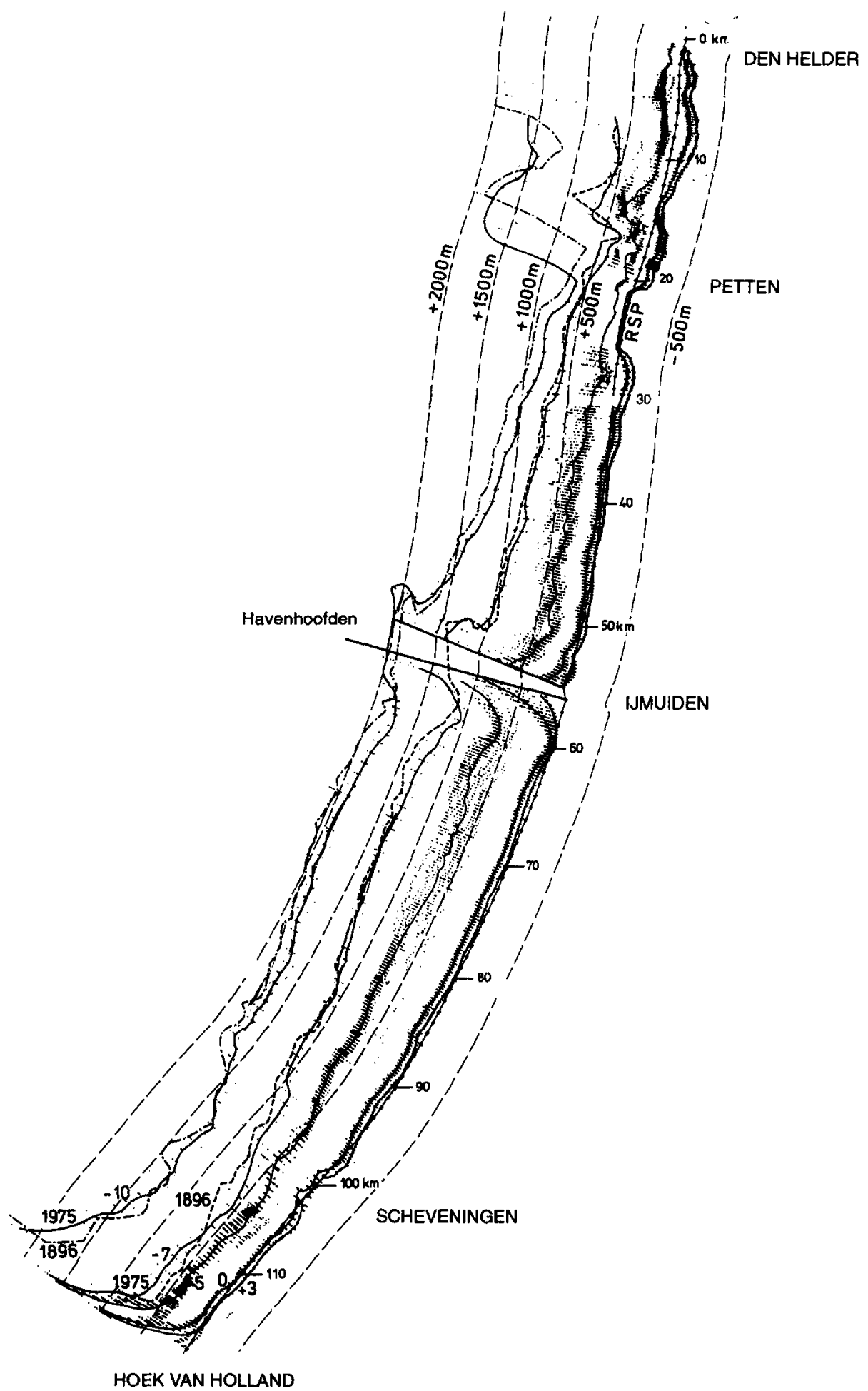




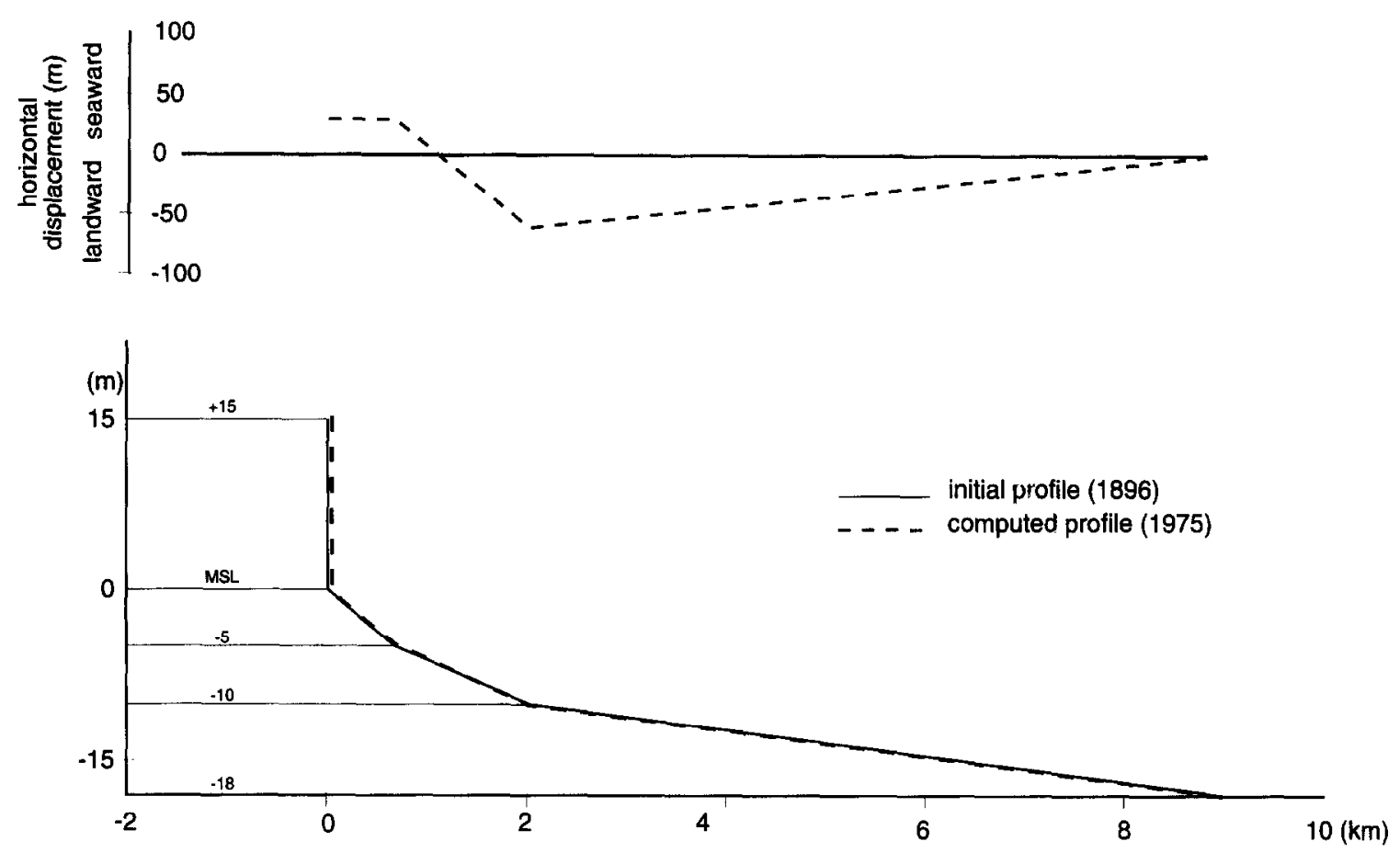

Fig. 4. Computed shoreface profile evolution 1896-1975 of the Central Holland Coast (km 70-90, see Fig. 3 for location).

have effectively reduced the degrees of freedom concerning the input into the model. In fact, the only free input parameter is the reference cross-shoreface transport, which we choose such that the volume gain of the upper shoreface section is reproduced.

As far as the bottom slope effect is concerned, we must conclude that the results obtained with the present formulation do not yield results which differ substantially from results based on initial estimates of the cross-shoreface transports. In this particular case the effects of changing bottom slopes are apparently minor, and justify the assumption that the response of the profile is proportional to the change in sea level.

\section{Subboreal/Subatlantic ( 5000 yrs B.P. - 2200 yrs B.P.) evolution of the Central Holland Coast}

As illustrated in Fig. 5, the morphology of the pre-transgressional surface of the Central Holland Coast gives a shoreline in the late Atlantic consisting of two protruding headlands separated by a large tidal basin (Beets et al., 1992). Due to the relatively strong decrease of the rate of sea-level rise around 6000 yrs B.P. an oversupply of sediment to the basin resulted in silting up of the tidal inlets since shortly before 5000 yrs B.P., which was followed by a barrier progradation lasting more than 3000 yrs. The shoreface profile evolution that occurred during the strong transgression can be inferred from ${ }^{14} \mathrm{C}$ gradients (see Fig. 6, Van der Valk, 1992). The prograding barrier sequence enclosed between the two headlands forms a virtually closed system. Available sources for the sediment supply are thought to be (cf. Beets et al., 1992) erosion of the headlands and redistribution of the sediment contained in the many ebb tidal deltas of the tidal inlets which silted up between 5000 yrs B.P. and 3300 yrs B.P. The primary driving mechanism behind these alongshore diffusive processes is most likely the wavedriven alongshore sediment transport, which reaches its maximum intensity on the upper shoreface.

Application of the present model to this Subboreal/Subatlantic evolution of the Central 


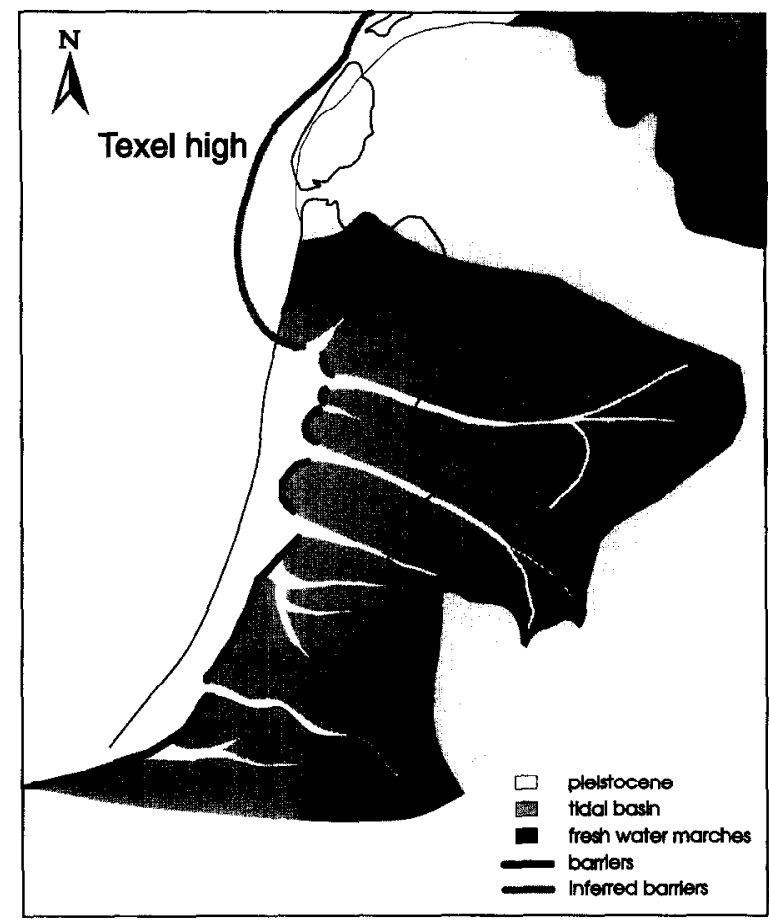

Fig. 5. Simplified palaeographic map of the western and northern Netherlands at about 5000 yrs B.P. (after Beets et al., 1992, and Van der Spek and Beets, 1992).

Holland Coast would provide a severe test. We have made a panel schematization of the inferred shoreface profile around 5000 yrs B.P., and applied the model without changing the input to the model other than introducing the observed mean rate of sea-level rise $(0.001 \mathrm{~m} / \mathrm{yr})$ and estimating the alongshore feeding of the upper shoreface $(25$ $\mathrm{m}^{3} / \mathrm{m} / \mathrm{yr}$, as a first-order estimate assumed to be constant) from the overall mass balance. Comparison of the hindcasted shoreface profile evolution with the inferred evolution (Fig. 6) indicates that the middle shoreface profile gradients are too steep, but that the overall hindcast is surprisingly good, considering that

(1) the internal dynamics of the model were the same as in the previous case,

(2) the only frec input parameter consists of the alongshore feeding of the upper shoreface, and

(3) all input parameters are assumed constant in time.

Obviously, there are many ways in which the model hindcast can be improved. We refrain from this, since we lack the data to make educated guesses about improved internal dynamics and inputs (e.g. time and depth varying longshore feeding). We remark only that a small increase of the slope term in the cross-shoreface transport formulation would lead to a morc realistic hindcast result for the middle shoreface panel. In fact, this slope term should map the response of all transport mechanisms to profile changes, whereas the present

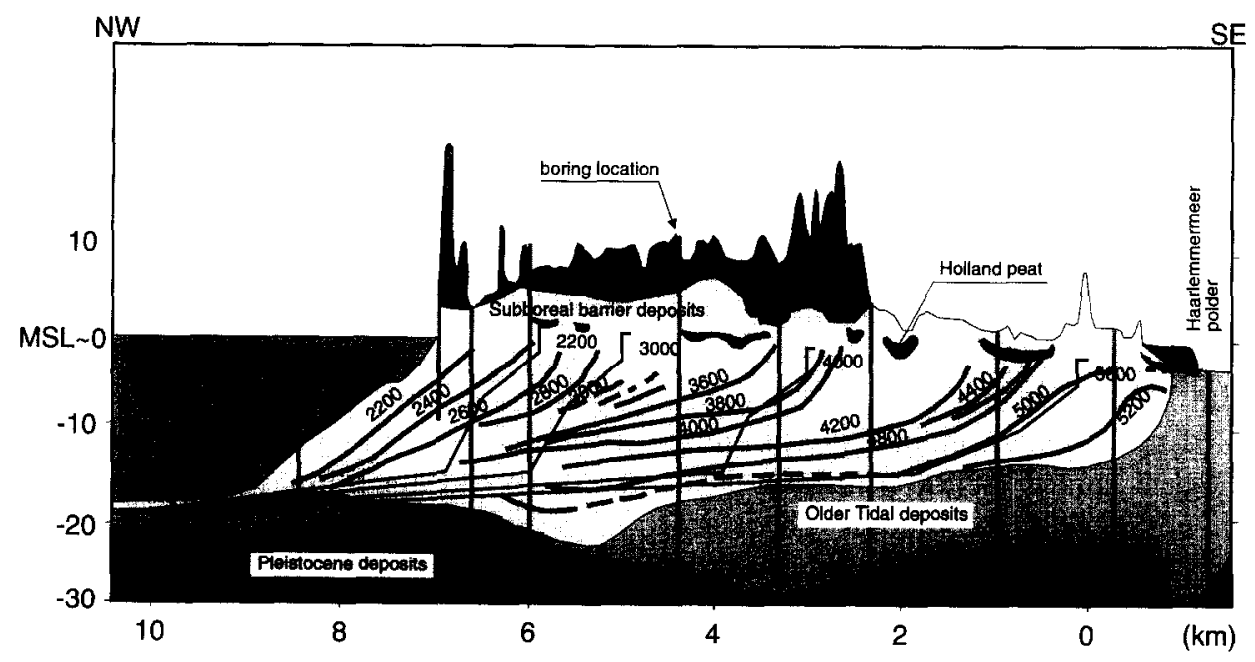

Fig. 6. Inferred (thick lines) ${ }^{14} \mathrm{C}$ gradients (after Van der Valk, 1992) and hindcasted (thin lines) Subboreal/Subatlantic shoreface profile evolution (5000-2200 yrs B.P.) of the Central Holland Coast. 
model includes only the wave-related mechanisms and ignores long-wave, tidal and geostrophic effects. Hence the required increase of the slope term most probably lies within the uncertainty band of the model.

\section{Discussion and conclusions}

Present knowledge of shoreface hydro-, sediment and morpho-dynamics is insufficient to undertake shoreface profile evolution modelling on the basis of first physical principles (cf. Niedoroda et al., 1994). Therefore, we propose a simple, panel-type model. The internal dynamics are determined by slope-dependent, wave-induced cross-shoreface transports, while the external driving factors are lateral sediment supply and sea-level rise. This model concept was tested against the observed behaviour of the Central Holland Coast. Two hindcast periods were considered, one covering the evolution over the last century, the other the Subboreal/Subatlantic evolution. Without varying any input variables to the model but the sediment supply to the upper shoreface, a reasonable hindcast of the observed evolutions was realized.

The three hinged rigid panels represent three distinct morphological shoreface zones. The upper shoreface, which includes the duneface, beach and surfzone, is assumed to respond rapidly to the driving conditions, with an assumed invariance of the "mean" profile relative to mean sea level. The lower shoreface which reaches down to the inner continental shelf is assumed to respond much slower to the coastal boundary layer conditions. The middle shoreface naturally forms a transition zone and is assumed to adapt itself to the upper and lower shoreface displacements.

For the model to be generally applicable, the transition points between the zones have to be chosen on the basis of physical arguments. The seaward end of the upper shoreface, for instance, would be a logical choice for the transition point between the upper and the middle shoreface. Hallermeier's (1981) depth of closure could be used as an indication of the depth at which this point is located, but we have to realize that this quantity depends on the time scale of consideration (Stive et al., 1992).
The location of the lower transition point, between the middle and lower shoreface, is even more unclear. Hallermeier (1981) gives suggestions to formulate a depth below which the surface waves do not affect the bed, but as the criteria can only be vague (unless there is a distinct threshold of motion and the near-bed water motion is not affected by tides, etc.), it is difficult to clearly specify this level. So far, the choice we have made for the Holland Coast model $(-10 \mathrm{~m})$ is rather arbitrary.

An important limitation of the model presented is that the cross-shoreface dynamics are solely steered by the variations of short waves as they shoal over the decreasing depths. As discussed in the introduction, a variety of other wave (e.g. Roelvink and Stive, 1989) and current dynamics (e.g. Niedoroda and Swift, 1991) may be expected to be present in the shoreface environment. Detailed local measurements as performed by Wright et al. (1991) on the shoreface of the Middle Atlantic Bight indicate that the net, long-term cross-shoreface transport is probably the residual of large and complicated offshore and onshore fluxes of sediment, which vary considerably under storm, fairweather and moderate energy conditions. Incident short wave action was found to be the major cause of bed shear stress, while lowfrequency wave effects were found to be of secondary importance. In our model only a limited number of these mechanisms is represented, viz. onshore fluxes due to wave asymmetry and wave driven bottom boundary layer flow and offshore fluxes due to short wave bottom slope interaction, in either case for high energy conditions only. It may well be that the effects of the mechanisms and conditions which are not represented are hidden in the cocfficients of the scdiment-transport formula. Therefore, one cannot attribute a large accuracy to the coefficients as used, and our findings should be considered as an-order-ofmagnitude estimate only. Indeed, behaviouroriented modelling implies that straightforward generalization to arbitrary situations and condilions is not possible. Yet, we expect that the approach as such and some of the conclusions are more generally applicable.

The assumption that the upper shoreface responds on a much smaller time scale than the 
lower shoreface has been made and substantiated by many other investigators (e.g. De Vroeg et al., 1988). The idea that the shoreface profile is not always and everywhere in equilibrium with its forcing also seems rather generally applicable, though obviously not everywhere with the same parameter setting. The most difficult, and probably the least validated part of the model is the crossshoreface transport description, which is a vital part of this transient profile evolution model, at least at larger time scales.

A most interesting observation from the Holland Coast application is, that the bottom slope effect on the transport is only important at geological time scales, and that the profile evolution at the engineering time scales ( 10 to 100 years) tends to follow the mean sea level in a more or less quasisteady way. This implies that at these smaller scales the profile changes can be predicted on the basis of a static sediment balance (cf. Stive et al., 1990). Note, however, that this does not mean that the gravitational downslope transport is unimportant as a physical phenomenon in coastal profile evolution (cf. Roelvink and Broker, 1993): We only state that it can be ignored in the present highly aggregated model if this is applied at relatively short time scales.

\section{Acknowledgements}

A large part of this paper is based on work in the "G8 Coastal Morphodynamics" research pro- gramme, which is funded partly by the Commission of the European Communities in the framework of the Marine Science and Technology Programme (MAST), under contract no. MAS2-CT92-0027. The work is co-sponsored by Delft Hydraulics, in the framework of the Netherlands Centre for Coastal Research, and by the Generalitat de Catalunya, in the framework of the Researchers of Excellence Programme for Catalan Universities.

The authors wish to acknowledge the useful comments of many of their colleagues on earlier versions of the manuscript, especially José Jimenez, Hans Wiersma, and Bert van der Valk. Very helpful in making the final version have been the detailed comments and discussions brought up by one of the reviewers.

\section{Appendix}

Based on the wave climate 1975-1986 (Hokke and Roskam, 1987) as measured at the platform Mcctpost Noordwijk, which is representative for the Central Holland Coast, results are presented for the relative contributions of the wave classes to the cross-shoreface transport at a depth of $10 \mathrm{~m}$, weighed according to their occurrence frequency, and assuming normal incidence. This should give an idea of the dominant wave height period combinations in the shoreface transition zone. In order to investigate the relative importtantanance of bedload and suspended load, and of mean flow and asymmetry contributions we distinguish between these contributions. At the same time we wish to verify the second order Stokes' assumption, so instead we apply Rienecker and Fenton's (1981) higher order wave approximations to estimate the central odd and even

Table A1

Experimental results

\begin{tabular}{|c|c|c|c|c|c|c|c|c|}
\hline $\begin{array}{l}H_{\mathrm{mo}} \\
(\mathrm{m})\end{array}$ & $\begin{array}{l}T_{\mathrm{m} 0} \\
(\mathrm{~s})\end{array}$ & $\begin{array}{l}\text { occ freq } \\
\%\end{array}$ & TBFA & TBFM & TSFA & TSFM & TTOT & $\begin{array}{l}\text { TTOT } \\
\text { wghd }\end{array}$ \\
\hline 0.25 & 4.0 & 20.778 & 0.0000 & 0.0000 & 0.0000 & 0.0000 & 0.0000 & 0.0000 \\
\hline 0.75 & 4.5 & 36.462 & 0.0000 & 0.0000 & 0.0000 & 0.0000 & 0.0000 & 0.0000 \\
\hline 1.25 & 5.0 & 20.805 & 0.0000 & 0.0003 & 0.0000 & 0.0005 & 0.0008 & 0.0167 \\
\hline 1.75 & 5.3 & 11.741 & 0.0002 & 0.0017 & 0.0005 & 0.0040 & 0.0064 & 0.0751 \\
\hline 2.25 & 5.5 & 5.437 & 0.0008 & 0.0061 & 0.0030 & 0.0194 & 0.0293 & 0.1593 \\
\hline 2.75 & 6.0 & 2.710 & 0.0037 & 0.0202 & 0.0191 & 0.0863 & 0.1294 & 0.3507 \\
\hline 3.25 & 6.5 & 1.055 & 0.0126 & 0.0514 & 0.0811 & 0.2765 & 0.4215 & 0.4447 \\
\hline 3.75 & 7.0 & 0.567 & 0.0330 & 0.1087 & 0.1911 & 0.5264 & 1.099 & 0.6229 \\
\hline 4.25 & 7.5 & 0.267 & 0.0716 & 0.2008 & 0.6365 & 1.499 & 2.407 & 0.6428 \\
\hline 4.75 & 8.0 & 0.117 & 0.1329 & 0.3333 & 1.321 & 2.796 & 4.583 & 0.5362 \\
\hline 5.25 & 8.5 & 0.056 & 0.2168 & 0.5069 & 2.350 & 4.674 & 7.748 & 0.4339 \\
\hline 5.75 & 9.0 & 0.006 & 0.3160 & 0.7154 & 3.657 & 7.115 & 11.80 & 0.0708 \\
\hline
\end{tabular}


moments, which appear in Bowen's bottom and suspended load transport equations due to mean flow and asymmetry.

The total odd moments can be expanded in terms of central odd and even moments and the mean flow (e.g. Roelvink and Stive, 1988), which allows the distinction between bottom transport due to asymmetry (TBFA) and due to mean flow (TBFM) and suspended load transport due to asymmetry (TSFA) and due to mean flow (TSFM). The results of this exercise are given in Table A1, where we have used a fall velocity of $w=0.015 \mathrm{~m} / \mathrm{s}$ representative for the transition shoreface sediment, and efficiency values of $\varepsilon_{\mathrm{b}}=0.2$ and $\varepsilon_{\mathrm{s}}=$ 0.02 , respectively.

\section{References}

Bagnold, R.A., 1963. Mechanics of marine sedimentation. In: M.N. Hill (Editor), The Sea. Interscience, New York, 3, pp. $507-528$.

Bailard, J.A., 1981. An energetics total load sediment transport model for a plane sloping beach. J. Geophys. Res., 86: $10,938-10,954$.

Battjes, J.A., Sobey, R.J. and Stive, M.J.F., 1990. Nearshore circulation. In: The Sea; Ideas and Observations on Progress in the Study of the Seas. Wiley, New York.

Beets, D.J., Van der Valk, L. and Stive, M.J.F., 1992. Holocene evolution of the coast of Holland. Mar. Geol., 103: 423-443.

Bowen, A.J., 1980. Simple models of nearshore sedimentation; beach profiles and longshore bars. In: S.B. McCann (Editor), The Coastline of Canada. Geol. Surv. Can. Pap., 80-10: 1-11.

Bruun, P., 1962. Sea-level rise as a cause of shore erosion. J. Waterways Harbors Div., ASCE, 88(WW1): 117-130.

Cowell, P.J., Roy, P.S. and Jones, R.A., 1992. Shoreface translation model: Computer simulation of coastal-sandbody response to sea-level rise. Mathemat. Comput. Simulation, 33: 603-608.

Cowell, P.J., Roy, P.S. and Jones, R.A., 1994. Simulation of LSCB using a morphological behaviour model. Mar. Geol., 126: 45-61. (This Volume.)

Dean, R.G., 1991. Equilibrium beach profiles: Characteristics and applications. J. Coastal Res., 7(1): 53-84.

De Vriend, H.J., Capobianco, M., Chesher, T., De Swart, H.E., Latteux, B. and Stive, M.J.F., 1993. Approaches to long-term modelling of coastal morphology: A review. J. Coastal Eng., 21: 225-269.

De Vroeg, J.H., Smit, E.S.P. and Bakker, W.T. 1988. Coastal genesis. Proc. 21st Int. Conf. Coastal Eng. ASCE, New York, pp. 2825-2839.

Hallermeier, R.J., 1981. A profile zonation for seasonal sand beaches from wave climate. J. Coastal Eng., 4: 253-277.

Hokke, A.W. and Roskam, A.P., 1987. Measured wave climate in deep water. Rijkswaterstaat, Tidal Waters Div, Rep., GWAO-87.291. (In Dutch.)

Inman, D.L., Elwany, M.H.S. and Jenkins, S.A., 1993. Shorerise and bar-berm profiles on ocean beaches. J. Geophys. Res., 98(C10): 18,181-18,199.

Knoester, D., 1990. Morphology of the Holland coast. Rijkswaterstaat, Tidal Waters Div., Rep., GWAO-90.010. (In Dutch.)

Lippmann, T.C. and Holman, R.A., 1990. The spatial and temporal variability of sand bar morphology. J. Geophys. Res., 95: 11,575-11,590.

Longuet-Higgins, M.S., 1953. Mass transport in water waves. Philos. Trans. R. Soc., Ser. A, 245: 535-581.

Niedoroda, A.W. and Swift, D.J.P., 1991. Shoreface processes. In: J.B. Herbich (Editor), Handbook of Coastal and Ocean Engineering. Gulf Publ., Houston, 2, pp. 736-769.

Niedoroda, A.W., Reed, C.W., Swift, D.J.P., Arato, H. and Hoyanagi, K., 1994. Modeling shore-normal large-scale coastal evolution. Mar. Geol., 126: 181-199. (This Volume.)

Pilkey, O.H., Young, R.S., Riggs, S.R., Smith, A.W., Wu, H. and Pilkey, W.D., 1993. The concept of shoreface profile of equilibrium: A critical review. J. Coastal Res., 9(1): 255-278.

Rienecker, M.M. and Fenton, J.D., 1981. A Fourier approximation method for steady water waves. J. Fluid Mech, 104: 119-137.

Roelvink, J.A. and Broker, I., 1993. Cross-shore profile models. Coastal Eng., 21: 163-191.

Roelvink, J.A. and Stive, M.J.F., 1989. Bar-generating crossshore flow mechanisms on a beach. J. Geophys., Res., Vol. 94(C4): 4785-4800.

Stive, M.J.F. and Eysink, W.D., 1989. Prediction of coastal evolution 1990-2090; dynamic model of the coastal system of the Netherlands. Annex 3.1 to Tech. Rep. 5 Rijkswaterstaat. (In Dutch.)

Stive, M.J.F., Roelvink, J.A. and De Vriend, H.J., 1990. Largescale coastal evolution concept. Proc, 22nd Int. Conf. Coastal Eng. ASCE, New York, pp. 1962-1974.

Stive, M.J.F., De Vriend, H.J., Nicholls, R.J. and Capobianco, M., 1992. Shore nourishment and the active zone: A lime scale dependent view. Proc. 23rd Int. Conf. Coastal Eng. ASCE, New York, pp. 2464-2473.

Van der Spek, A.J.F. and Beets, D.J., 1992. Mid-Holocene evolution of a tidal basin in the western Netherlands: a model for future changes in the northern Netherlands under conditions of accelerated sea-level rise? Sediment. Geol., 80: 185-197.

Van der Valk, L., 1992. Mid- and Late-Holocene coastal evolution in the beach-barrier area of the western Netherlands. Ph.D. Thesis, Free Univ. Amsterdam, 235 pp.

Wright, L.D., Boon, J.D., Kim, S.C. and List, J.H., 1991. Modes of cross-shore sediment transport on the shoreface of the Middle Atlantic Bight. Mar. Geol., 96: 19-51. 